\title{
Frequency of Bone Injuries examined in the Emergency Departments of the Royal Medical Services hospital, Jordan
}

\author{
Ahmad Abedlaqader Aldhoun, Abedalbaset Talal Alzoubi*, Zuhier Ali Ikhwayleh, Issam Fahmi \\ Othman Alrbeihat, Ibrahim khalil Abu Hussein, Ashraf mohammad Sh A Odeh, Ahmad Khaled \\ Suleiman Almigdad \\ Royal Medical Services, Jordan
}

*Corresponding author: Abedalbaset Talal Alzoubi, Royal Medical Services, Jordan

\section{ARTICLE INFO}

Received: 幽 October 27, 2020

Published: November 05, 2020

Citation: Ahmad Abedlaqader A, Abedalbaset Talal A, Zuhier Ali I, Issam Fahmi Othman A, Ibrahim khalil Abu $\mathrm{H}$, et al. Frequency of Bone Injuries examined in the Emergency Departments of the Royal Medical Services hospital, Jordan. Biomed J Sci \& Tech Res 31(4)-2020. BJSTR. MS.ID.005139.

Keywords: Emergency Department; Injuries; Traffic Accidents; Falling Down; Injury Type; Injury Site

\section{ABSTRACT}

Introduction: Emergency department usually receives cases with bone injuries due to various causes including falling, accidents, and fire shooting.

Study Objectives: The main objectives of this study are to identify the frequency of bony lesions compared with other cases received in the emergency departments of the Royal Medical Services hospital, Jordan, and to identify types and causes of bony lesions.

\section{Methods and subjects:}

Study Design: A retrospective study design was conducted to collect data from files of patients.

Study sample: A total of 150 files for patients who visited emergency department were randomly selected.

Study Procedure: After obtaining the ethical approval from IRB committee, the researchers started reviewing patient files to extract data. All data were entered into excel spreading sheet. Data included the following variables age, gender, type of injury, and site of injury.

Data were analyzed using SPSS version 21. Data representation included means, standard deviation, frequencies and percentages. Relationships between variables were determined using Chi-Square test. Significance will be considered at $\alpha \leq 0.05$.

Results: Study findings showed that the mean of age was $30.13 \pm 18.60$ years, the majority of patient who were exposed to injuries were males (about 59\%), 74\% of patients were exposed to injuries resulting from falling down. According to injury site, injuries were more shown in lower body $58 \%$.

Conclusion: The results of the present study showed that males were more likely to have injuries compared with females. Females were more likely to be exposed to injuries resulting from falling down. No injury cases resulting from scrimmage among females.

\section{Introduction}

Fracture, a break in the basic progression of bone, is a significant musculoskeletal wellbeing concern around the world [1]. In distributed reports, the frequency of fractures changes and ranges from 3.21 to 22.8/1000 for each annum in the general population [2]. Recently distributed report additionally showed that furthest point breaks establish $82.1 \%-94.7 \%$ of all fractures by anatomical locale distribution [3-5]. Breaks of ordinary bones regularly results from high-energy sway or dull pressure while for bones unusually debilitated by malady typical burden or unimportant injury is enough to cause a fracture [6]. The outer reasons for limit cracks, for example, engine vehicular crashes, falls, sports injury, and attack are about the equivalent internationally. In any case, 
the appropriations of these etiological factors shift between and inside nations depending on winning segment profile, financial, furthermore, natural conditions. Some distributed reports show prevalence of falls as outside reasons for cracks among the pediatric and geriatric populaces, what's more, occupants of areas with a sloping terrain [7-10]. In some different reports, engine vehicular crash was the transcendent outer reason for breaks, particularly in areas where street traffic injury is an ignored epidemic $[8,9]$.

Right now, injury is the main source of death, hospitalization, and inability for all age gatherings, and that is the reason injury casualties are more probable executed more than different infections. Chest injury alone records for $45 \%$ of all injury related passing's. The way to analyze chest wounds is having a solid outlook about the probability of thoracic injury in harmed patients, in view of precise patient history $[11,12]$. The seriousness and sort of component that cause the injury is gotten and a huge level of wounds can be analyzed by basic paraclinical procedures, particularly by plain chest radiography [13]. Nonetheless, in under $15 \%$ of the wounds to the chest, crisis medical procedure is required. In different wounds, just steady consideration and early treatment are adequate. A significant number of these wounds are viewed as moderate in seriousness and require just a set number of careful mediations, and there is little uncertainty that such wounds are of specific significance [14]. Cautious development of these patients is basic and accommodating in distinguishing cases that require the treatment of activities [15]. Thoracic injury is perceived as a significant issue and its restorative noteworthiness is clear [16]. Among the breaks during the chest injury, cracks of the ribs are not regular in newborn children because of chest flexion, but rather are extremely basic in the older. Most rib breaks happen in the center aspect of the rib [17]. Upper breaks can be related with aortic and tracheal wounds and lower rib cracks with harm to the intra-stomach organs, including the kidney, spleen, and liver [18]. A few confirmations recommend that there is an immediate connection between age, expanded number of harmed ribs, and mortality $[19,20]$.

\section{Study Objectives}

The main objectives of this study were to identify the frequency of bony lesions compared with other cases received in the emergency department of the Royal Medical Services Hospital, and to identify types and causes of bony lesions.

\section{Methods and subjects}

Study Design: a retrospective study design was conducted to collect data from files of patients with injuries.

Study Sample: A total of 300 files for patients who visited emergency department were randomly selected. The valid files that involved clear data and were valid for analysis were 150 files.
Study Procedure: After obtaining the ethical approval from IRB committee, the researchers started reviewing files of patients to extract data. All data were entered into excel spreading sheet. Data included the following variables: age, gender, type of injury, and site of injury. Data were analyzed using SPSS version 21. Data representation included means, standard deviation, frequencies and percentages. Relationships between variables were determined using Chi-Square test. Significance was considered at $\alpha \leq 0.05$.

\section{Results}

\section{General Characteristics of Participants}

As indicated in Table 1, the mean of age was $30.13 \pm 18.60$ years, $58 \%$ of patients were less the age mean. The majority of patient who were exposed to injuries were males (about 59\%). A total of 111 (74\%) of patients were exposed to injuries resulting from falling down, traffic accidents were attributed to $18 \%$ of injuries, scrimmage related injuries were shown by $8 \%$ of patients. According to injury site, injuries were more shown in lower body (58\%) than in upper body (42\%).

Table 1: General characteristics of participants.

\begin{tabular}{|c|c|}
\hline Variable & Description \\
\hline Age (M \pm SD) years & $30.13 \pm 18.60$ \\
\hline Age (N, \%) years: & $87(58 \%)$ \\
$-\leq 30.133$ & $63(42 \%)$ \\
$->30.1333$ & \\
\hline Gender (N, \%): & $89(59.3 \%)$ \\
-Males & $61(40.7 \%)$ \\
-Females & \\
\hline Injury type (N, \%): & $27(18 \%)$ \\
-Accident (traffic) & $111(74 \%)$ \\
-Falling down & $12(8 \%)$ \\
-Scrimmage & \\
\hline Injury site (N, \%): & $63(42 \%)$ \\
-Upper body & $87(58 \%)$ \\
\hline -Lower body & \\
\hline
\end{tabular}

\section{Statistical Relationships Between Gender and Age with Other Study Variables}

As shown in Table 2, the gender was significantly associated with injury type $(\mathrm{p}=0.01)$. About $21 \%$ of females had traffic accidents, while about $16 \%$ of males had traffic accidents. Falling down injuries were shown by $79 \%$ of females, and $71 \%$ males. Scrimmage related injuries were not reported for females and restricted to males. As seen in Table 3, there was no statistically significant relationship between gender and injury site $(\mathrm{p}=0.383)$. Lower parts of the body had injuries in $55.7 \%$ females, and $59.6 \%$ of males. On the other hand, injuries in upper parts of the body 
were shown in $44.3 \%$ of females and $40.4 \%$ of males. As seen in Table 4 , there was no statistically significant differences between the age and injury site $(p=0.374)$. In the age group $\leq 30.133$, lower parts and upper parts of the body had similar trends. In the older age group, lower parts of the body had $60 \%$ of injuries, whereas upper parts of the body had about $40 \%$ of injuries. As shown in Table 5, there was no statistically significant relationship between age and injury type $(\mathrm{p}=0.832)$. Injury types were almost close to each other in age groups.

Table 2: The relationship between gender and injury type.

\begin{tabular}{|c|c|c|c|c|c|c|c|}
\hline & & & \multicolumn{3}{|c|}{ Injury type } & \multirow{2}{*}{ Total } & \multirow{2}{*}{$P$ value } \\
\hline & & & Traffic accident & Falling down & Scrimmage & & \\
\hline \multirow{8}{*}{ Gender } & \multirow{4}{*}{$\mathrm{F}$} & Count & 13 & 48 & 0 & 61 & 0.01 \\
\hline & & $\%$ within Gender & $21.30 \%$ & $78.70 \%$ & $0.00 \%$ & $100.00 \%$ & \\
\hline & & $\%$ within Injury type & $48.10 \%$ & $43.20 \%$ & $0.00 \%$ & $40.70 \%$ & \\
\hline & & $\%$ of Total & $8.70 \%$ & $32.00 \%$ & $0.00 \%$ & $40.70 \%$ & \\
\hline & \multirow{4}{*}{ M } & Count & 14 & 63 & 12 & 89 & \\
\hline & & $\%$ within Gender & $15.70 \%$ & $70.80 \%$ & $13.50 \%$ & $100.00 \%$ & \\
\hline & & $\%$ within Injury type & $51.90 \%$ & $56.80 \%$ & $100.00 \%$ & $59.30 \%$ & \\
\hline & & $\%$ of Total & $9.30 \%$ & $42.00 \%$ & $8.00 \%$ & $59.30 \%$ & \\
\hline \multirow{4}{*}{\multicolumn{2}{|c|}{ Total }} & Count & 27 & 111 & 12 & 150 & \\
\hline & & $\%$ within Gender & $18.00 \%$ & $74.00 \%$ & $8.00 \%$ & $100.00 \%$ & \\
\hline & & $\%$ within Injury type & $100.00 \%$ & $100.00 \%$ & $100.00 \%$ & $100.00 \%$ & \\
\hline & & $\%$ of Total & $18.00 \%$ & $74.00 \%$ & $8.00 \%$ & $100.00 \%$ & \\
\hline
\end{tabular}

Table 3: The relationship between gender and injury site.

\begin{tabular}{|c|c|c|c|c|c|c|}
\hline & & & \multicolumn{2}{|c|}{ Injury site } & \multirow{2}{*}{ Total } & \multirow{2}{*}{$P$ value } \\
\hline & & & Lower & Upper & & \\
\hline \multirow{8}{*}{ Gender } & \multirow{4}{*}{$\mathrm{F}$} & Count & 34 & 27 & 61 & \multirow{12}{*}{0.383} \\
\hline & & $\%$ within Gender & $55.7 \%$ & $44.3 \%$ & $100.0 \%$ & \\
\hline & & $\%$ within Injury site & $39.1 \%$ & $42.9 \%$ & $40.7 \%$ & \\
\hline & & $\%$ of Total & $22.7 \%$ & $18.0 \%$ & $40.7 \%$ & \\
\hline & \multirow{4}{*}{ M } & Count & 53 & 36 & 89 & \\
\hline & & $\%$ within Gender & $59.6 \%$ & $40.4 \%$ & $100.0 \%$ & \\
\hline & & $\%$ within Injury site & $60.9 \%$ & $57.1 \%$ & $59.3 \%$ & \\
\hline & & $\%$ of Total & $35.3 \%$ & $24.0 \%$ & $59.3 \%$ & \\
\hline \multirow{4}{*}{\multicolumn{2}{|c|}{ Total }} & Count & 87 & 63 & 150 & \\
\hline & & $\%$ within Gender & $58.0 \%$ & $42.0 \%$ & $100.0 \%$ & \\
\hline & & $\%$ within Injury site & $100.0 \%$ & $100.0 \%$ & $100.0 \%$ & \\
\hline & & $\%$ of Total & $58.0 \%$ & $42.0 \%$ & $100.0 \%$ & \\
\hline
\end{tabular}

Table 4: The relationship between age and injury site.

\begin{tabular}{|c|c|c|c|c|c|c|}
\hline & & & \multicolumn{2}{|c|}{ Injury site } & \multirow{2}{*}{ Total } & \multirow{2}{*}{$P$ value } \\
\hline & & & Lower & Upper & & \\
\hline \multirow{8}{*}{ Age } & \multirow{4}{*}{$\leq 30.133$} & Count & 49 & 38 & 87 & \multirow{8}{*}{0.374} \\
\hline & & $\%$ within age & $56.3 \%$ & $43.7 \%$ & $100.0 \%$ & \\
\hline & & $\%$ within injury site & $56.3 \%$ & $60.3 \%$ & $58.0 \%$ & \\
\hline & & $\%$ of Total & $32.7 \%$ & $25.3 \%$ & $58.0 \%$ & \\
\hline & \multirow{4}{*}{$>30.1331$} & Count & 38 & 25 & 63 & \\
\hline & & $\%$ within age & $60.3 \%$ & $39.7 \%$ & $100.0 \%$ & \\
\hline & & $\%$ within injury site & $43.7 \%$ & $39.7 \%$ & $42.0 \%$ & \\
\hline & & $\%$ of Total & $25.3 \%$ & $16.7 \%$ & $42.0 \%$ & \\
\hline
\end{tabular}




\begin{tabular}{|c|c|c|c|c|}
\hline \multirow{4}{*}{ Total } & Count & 87 & 63 & 150 \\
\cline { 2 - 5 } & \% within age & $58.0 \%$ & $42.0 \%$ & $100.0 \%$ \\
\cline { 2 - 5 } & \% within injury site & $100.0 \%$ & $100.0 \%$ & $100.0 \%$ \\
\cline { 2 - 5 } & \% of Total & $58.0 \%$ & $42.0 \%$ & $100.0 \%$ \\
\hline
\end{tabular}

Table 5: The relationship between age and injury type.

\begin{tabular}{|c|c|c|c|c|c|c|c|}
\hline & & & \multicolumn{3}{|c|}{ Injury type } & \multirow{2}{*}{ Total } & \multirow{2}{*}{$P$ value } \\
\hline & & & Traffic accident & Falling down & Scrimmage & & \\
\hline \multirow{8}{*}{ Age } & \multirow{4}{*}{$\leq 30.133$} & Count & 17 & 63 & 7 & 87 & \multirow{12}{*}{0.832} \\
\hline & & $\%$ within age & $19.5 \%$ & $72.4 \%$ & $8.0 \%$ & $100.0 \%$ & \\
\hline & & $\%$ within injury type & $63.0 \%$ & $56.8 \%$ & $58.3 \%$ & $58.0 \%$ & \\
\hline & & $\%$ of Total & $11.3 \%$ & $42.0 \%$ & $4.7 \%$ & $58.0 \%$ & \\
\hline & \multirow{4}{*}{$>30.1331$} & Count & 10 & 48 & 5 & 63 & \\
\hline & & $\%$ within age & $15.9 \%$ & $76.2 \%$ & $7.9 \%$ & $100.0 \%$ & \\
\hline & & $\%$ within injury type & $37.0 \%$ & $43.2 \%$ & $41.7 \%$ & $42.0 \%$ & \\
\hline & & $\%$ of Total & $6.7 \%$ & $32.0 \%$ & $3.3 \%$ & $42.0 \%$ & \\
\hline \multirow{4}{*}{\multicolumn{2}{|c|}{ Total }} & Count & 27 & 111 & 12 & 150 & \\
\hline & & $\%$ within age & $18.0 \%$ & $74.0 \%$ & $8.0 \%$ & $100.0 \%$ & \\
\hline & & $\%$ within injury type & $100.0 \%$ & $100.0 \%$ & $100.0 \%$ & $100.0 \%$ & \\
\hline & & $\%$ of Total & $18.0 \%$ & $74.0 \%$ & $8.0 \%$ & $100.0 \%$ & \\
\hline
\end{tabular}

\section{Discussion}

The present study showed that the mean age of study participants was about 30 years. This means that young people are more likely to be affected by injuries. This may indicate that due to productivity of this group of patients, which requires more using of traveling. This result is consistent with other studies such as the study of Kalani et al. The present study showed that males were more likely to be involved in injuries. This may reflect the dynamics of Jordan community in which more males are involved in labor market and military forces, a matter that increase the chances for injuries by males. Recently, the study of Kalani et al also indicated that males were more likely to be involved in injuries.

The results of the present study showed that injuries resulting from falling down made the most frequent injuries. However, the study of Kalani et al reported different trends in which falling down frequencies were within minimal levels as compared with other injuries. Other studies are consistent with our findings. The results of the present study showed that injuries in the lower parts of the body was more predominant than injuries in the upper parts of the body. This is in line with other studies such as the studies of Donaldson. The results of the present study showed that gender was significantly associated with injury type, and females were more likely to have injuries resulting from falling down. Other studies did not report such differences.

\section{Conclusion}

The results of the present study showed that males were more likely to have injuries compared with females. Females were more likely to be exposed to injuries resulting from falling down. No injury cases resulting from scrimmage among females.

\section{References}

1. Omoke NI, Ekumankama FO (2020) Incidence and pattern of extremity fractures seen in accident and emergency department of a Nigerian teaching hospital. Niger J Surg 26(1): 28-34.

2. Larsson E, Lindström A, Eriksson M (2019) Impact of gender on posttraumatic intensive care and outcomes. Scand J Trauma Resusc Emerg Med 27(1): 115.

3. Haider AH, Crompton JG, Oyetunji T (2009) Females have fewer complications and lower mortality following trauma than similarly injured males: a risk adjusted analysis of adults in the National Trauma Data Bank. Surgery 146(2): 308-315.

4. Donaldson LJ, Cook A, Thomson RG (1990) Incidence of fractures in a geographically defined population. J Epidemiol Community Health 44: 2415.

5. Chen W, Lv H, Liu S, Liu B, Zhu Y, et al. (2017) National incidence of traumatic fractures in China: A retrospective survey of 512187 individuals. Lancet Glob Health 5(8): e807-817.

6. Babalola OM, Salawu ON, Ahamed BA, Ibraheem GH, Olawepo A (2018) Epidemiology of traumatic fractures in a tertiary health center in Nigeria. J Orthop Traumatol Rehabil 10(2): 87-96.

7. Chigblo P, Lawson E, Tidjani IF, Padonou A, Nezien CT (2017) Epidemiology of fractures in a tropical country. Eur Sci J 13(24): 416426.

8. Nayagama S (2010) Principles of fractures Apley's Systems of Orthopaedics and Fractures. In Solomon L, Warwick DJ, Nayagama S (Eds.), ( $9^{\text {th }}$ edn.), Hachette UK Company, Hodder Arnold, London pp. 687-688.

9. Alomran AK, Bubshait DA, Sadat Ali M (2012) Epidemiology of paediatric fractures and dislocations: Analysis of in patients. Bahrain Med Bull 34(4): 1-7. 
10. Janmohammadi N, Montazeri M, Akbarnezhad E (2014) The epidemiology of extremity fracture in trauma patient of Shahid Beheshti hospital Babol 2001-2006.Iran J Emerg Med 1: 34-39.

11. Awashthi B, Raina SK, Kumar N, Sharma V, Kalia S (2016) Pattern of extremity fractures among patient with musculoskeletal injuries. A hospital based study from North India. India J Med Soc 30(1): 37-47.

12. Sadat Ali M, Alomran AS, Al Sayed HN, Al Dhafar BA, Kub bara AF (2015) Epidemiology of fractures and dislocations among urban communities of Eastern Saudi Arabia. Saudi J Med Sci 3: 54-57.

13. Kalani N, Habibzadeh SR, Ghahremanizadeh R, Tavakolian A, Hatam N (2020) Diagnostic Accuracy of Physical Examination and History Taking in Traumatic Rib Fracture; A Single Center Experience. Bulletin of emergency and trauma 8(2): 111-114

14. Ebrahimi M, Vaziri M, Pishbin E, Reihani H, Akhavan R, et al. (2019) Comparison of Diagnostic Value of Clinical Examination and Routine Radiography in Diagnosis of Chest Injury in Stable Blunt Trauma Patients. Journal of Research in Medical and Dental Science 7(1): 88-91.

15. Bakirbaevich YK, Toktosunovich YI, Muktarovich KK (2018) Analysis of mortality cases from concomitant injuries: extracranial injuries combined with craniocerebral injuries. European journal of biomedical and life scences 3: 13-17.

\section{ISSN: 2574-1241}

DOI: 10.26717/BJSTR.2020.31.005139

Abedalbaset Talal Alzoubi. Biomed J Sci \& Tech Res

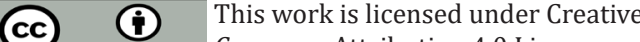

Submission Link: https://biomedres.us/submit-manuscript.php
16. Ngahane BHM, Kamdem F, Njonnou SRS, Chebou N, Dzudie A, et al. (2019) Epidemiology, Clinical and Paraclinical Presentations of Pulmonary Embolism: A Cross-Sectional Study in a Sub-Saharan Africa Setting. Open Journal of Respiratory Diseases 9(3).

17. Schulz Drost S, Grupp S, Pachowsky M, Oppel P, Krinner S, et al. (2017) Stabilization of flail chest injuries: minimized approach techniques to treat the core of instability. Eur J Trauma Emerg Surg 43(2): 169-178.

18. Ignore HM, Eardley W, McDaid C, Rangan A, Lawrence T (2020) Epidemiology of adult rib fracture and factors associated with surgical fixation: Analysis of a chest wall injury dataset from England and Wales. Injury 51(2): 218-223.

19. Rostas JW, Lively TB, Brevard SB, Simmons JD, Frotan MA (2017) Rib fractures and their association with solid organ injury: higher rib fractures have greater significance for solid organ injury screening. Am J Surg 213(4): 791-797.

20. Lin FC, Li RY, Tung YW, Jeng KC, Tsai SC (2016) Morbidity, mortality, associated injuries, and management of traumatic rib fractures. J Chin Med Assoc 79(6): 329-334.

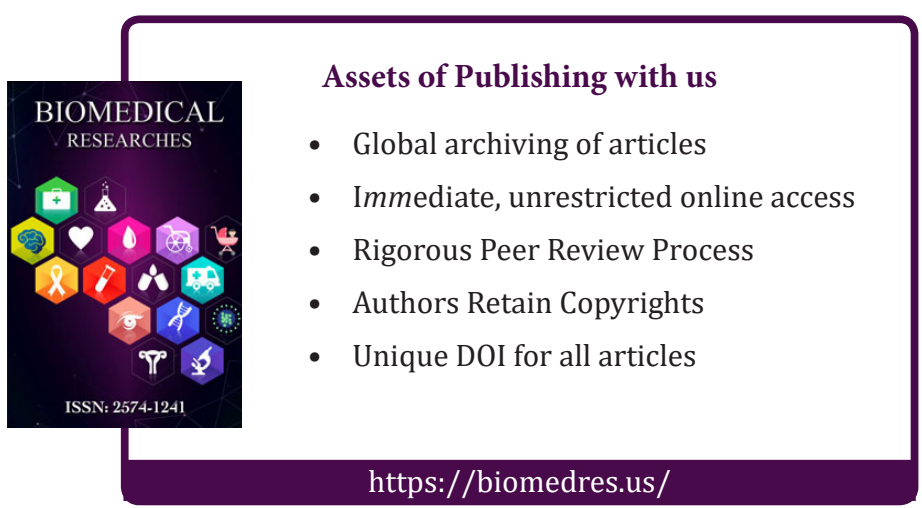

